\title{
A paleontologia ilimitada do país de Ameghino
}

\section{The unlimited paleontology of the country of Ameghino}

\author{
Maria Margaret Lopes ${ }^{i}$ \\ ' Orientadora plena, Programa de Pós-graduação Interunidades em Museologia, \\ Museu de Arqueologia e Etnologia/Universidade de São Paulo. \\ São Paulo - SP - Brasil \\ orcid.org/0000-0002-9803-8378 \\ mmlopes@usp.br
}

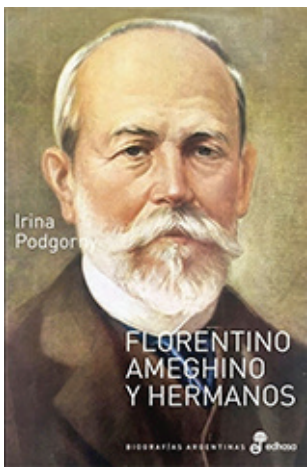

PODGORNY, Irina. Florentino Ameghino y Hermanos: empresa argentina de paleontología ilimitada. Buenos Aires: Edhasa, 2021. 348p.
Florentino Ameghino (1854?-1911) dispensa apresentações para os historiadores das ciências, em especial da paleontologia, da zoologia, da antropologia, da etnografia, da arqueologia. Sua vasta obra, referência obrigatória para os especialistas europeus e norteamericanos de sua época, de Paris a Princeton, permanece consulta imprescindível, não só para a história da geologia, da paleontologia, da antropologia, da historiografia latino-americana, como para o esclarecimento de prioridades de pesquisas.

É certo que desde sua morte não faltaram obituários, biografias laudatórias do "sábio", notas nas revistas científicas internacionais das diversas áreas disciplinares para as quais Ameghino deixou suas inúmeras contribuições.

A contribuição original de Florentino Ameghino y Hermanos: empresa argentina de paleontología ilimitada é justamente sua abordagem inovadora. As fontes inéditas e a articulação de inúmeras temáticas são marcas características da produção da autora.

Florentino Ameghino y Hermanos se apoia em inúmeras fontes arquivísticas, textos de época, jornais diários, a imensa correspondência de Ameghino, publicações científicas de diversos períodos, quadrinhos para crianças. Um trabalho enorme. Articula de maneira sofisticada vastíssima bibliografia atualizada, tanto argentina quanto internacional. De cada um dos dez capítulos - que em nada que se assemelham ao gênero biográfico cronológico - surgem episódios menos conhecidos da trajetória da empresa familiar, das tramas e intrigas cotidianas, deliciosas de serem acompanhadas, aspectos das histórias políticas e científicas da Argentina, das "histórias sem palavras" da paleontologia e da arqueologia, que se entrelaçam na trajetória de Ameghino e irmãos.

Para traçar a "presença perturbadora" de indivíduos em qualquer história coletiva - que é o objetivo desse livro -, a autora propõe que conheçamos perfis inusitados de Ameghino 
e de seus variados sócios. Esses não foram contemplados pela vasta literatura laudatória construída em torno do maestro de campaña, que a abundância dos fósseis de Lujan, Mercedes (Capítulo 1), ou quaisquer outras barrancas de rios na Argentina transformou em promessa de glória, nacionalizando Ameghino, tal qual a origem argentina da humanidade, seu "homem fóssil" que conviveu com os gliptodontes e tanto nos fascina, como Irina Podgorny escreveu.

O perfil de Ameghino na literatura científica, popularizado amplamente na Argentina e por toda a América Latina, foi moldado pelos meios de que ele fartamente se utilizou, por intermédio do comércio eficiente e lucrativo de fósseis, da corrida por prioridades em publicações, por proeminência na imprensa, articulando redes que envolviam desde a comunidade italiana argentina, especialistas em aluguéis, amigos e inimigos, burocratas de governos, partidos políticos, funcionários das estradas de ferro, estancieiros, até reconhecidos pesquisadores italianos, franceses, ingleses, alemães, norte-americanos, brasileiros e a família é claro: os irmãos e a esposa - que só aparece em sua figura trágica ao final do livro. Ameghino, como a obra bem retrata, poderia ser um exemplo claro da construção da "persona científica", de que Lorraine Daston e Sibum (2003) nos falam. Traçar "perfis caleidoscópicos" - para usar os termos de Olival Freire Jr. (2020) - de todo um conjunto de agentes e agências pelos quais circulou Ameghino foi um dos maiores desafios que o livro enfrentou e o fez muito bem.

Na primeira parte da obra, a venda dos fósseis de Ameghino e outros sócios, na Exposição Universal de Paris, de 1878 (Capítulo 2), explora o comércio que alicerçou sua carreira, tão expressivo na conformação das ciências naturais, e o conjunto de estratégias e expertises necessárias para o viabilizar.

A concreta possibilidade de construção de práticas científicas coletivas, em espaços pouco institucionalizados, é evidenciada em vários momentos, desde os primeiros aos últimos capítulos do livro. Ameghino, com falsa modéstia, recorrendo à retórica científica dos grandes mestres, entre moluscos e mamíferos (Capítulo 4), corre por fora de espaços institucionais formais, em projetos de museus e empregos que não se concretizam durante a maior parte de sua vida, até seus poucos anos no Museu de La Plata e de Buenos Aires. Milhares de novos animais extintos se amontoavam, em sua papelaria, atrás das estantes de material escolar. Suas librerias del Glyptodonte (Capítulo 3), verdadeiros "centros de cálculo" de Latour, atraindo pesquisadores internacionais que circularam pelo mundo, foram o verdadeiro "campo" para muitos paleontólogos estrangeiros, que nem precisaram percorrer os afloramentos fossilíferos de difícil acesso e, aliás estrategicamente pouco referenciados, apesar de o irmão Carlos se empenhar cuidadosamente por coletar, classificar e transportar os fósseis encontrados. Amontoavam-se nas inúmeras obras que publicava na França ou na Argentina, nas páginas dos periódicos das instituições científicas e também agora nos meandros das negociações descritas em Florentino Ameghino y Hermanos.

A primeira parte da empresa argentina continua trazendo as articulações que marcaram sucessos e malogros do empreendimento familiar: os agentes e agências envolvidos; o êxito familiar versus a debilidade institucional; o apoio fundamental de um amigo, a originalidade, o lançamento oportuno de sua classificação filogenética, seguido de Mortillet, Haeckel, Gaudry, que tornaram Ameghino um instrumento anticlerical na luta política 
argentina (Capítulo 5); um cargo na universidade de Córdoba, acompanhado por mais umas quarenta espécies novas de ossos, deixando Juan na livraria de Buenos Aires e Carlos no campo na coleta de mais ossos; "as amizades tão efêmeras quanto os acordos políticos", as disputas, colaborações, mudanças de alianças científicas que marcaram a expedição ao Chaco (Capítulo 6); finalmente um cargo, que duraria pouco, no novo Museu de La Plata que se construía, uma "evocação da 'coleção de peças grandes'”, 1 cobiçadas pelos estrangeiros - características dos delírios dos museus por todo o mundo; os altos custos dos empreendimentos para transformar Monte Hermoso na llanura terciária (planície terciária) argentina; ou para manter Carlos na Patagônia, envolvendo erva-mate, correio, mulas, papel, financiamentos internacionais em troca de envios de fósseis para conhecidos paleontólogos como Zittel em Munique (Capítulo 7); ou acordos duradouros por décadas de pesquisa como o de Ameghino, von Ihering \& Co., tratado em detalhes em meio à controvérsia sobre a Patagônia com os americanos de Princeton, professores dos museus de Paris, Nova York ou Munique que não podiam acreditar na exuberância dessas faunas de quando a Argentina foi uma ilha... (já no Capítulo 9, na segunda parte do livro). Aí a paleontologia da Patagônia inverte as sucessivas estratigrafias de Ameghino, ao lado de um Glyptodon baratíssimo, que a espetacularidade e a quantidade das ossadas fósseis relativamente fáceis de serem encontradas no território argentino, o trabalho de Ameghino publicizado pelos jornais e nas escolas popularizava.

A obra monumental de 1.027 páginas, fartamente ilustrada com as 570 espécies de mamíferos fósseis até então desconhecidos, dos quais 450 haviam sido criados por Ameghino, e fizeram o esplendor argentino desde os tempos geológicos, abre a segunda parte de Florentino Ameghino y Hermanos. Alimenta os "ataques pessoais" na obra financiada com dinheiro público, exposta em Paris, tão comum nos prólogos de muitas publicações científicas, pelo menos do século XIX: "provavelmente o único que se lia em Buenos Aires, porém irrelevante fora do país". ${ }^{2}$ As negociações necessárias para Ameghino manter-se fora do Museu de La Plata, em melhores condições em sua libreria, mesclam-se à relevância que a fauna dos territórios da Patagônia ganhou para a estratigrafia geológica do sul da América, a utilidade da taquigrafia inventada por Ameghino, a sobrevivência de Carlos no campo e a necessidade de ocultar afloramentos para proteger seu espólio são apenas alguns dos aspectos que fizeram parte da construção da paleontologia do sul da América (Capítulo 8).

No último capítulo acompanhamos Ameghino em busca de seu próprio museu, que dirigiria por poucos anos com grande propaganda internacional, mesmo sem conseguir um novo edifício. Novas disputas de Ameghino, agora em Buenos Aires, e novas ousadias sobre os precursores argentinos da humanidade, imerso nos debates internacionais centrais da época. Começa a se esboçar o tema de um novo livro de Irina Podgorny, que acaba de ser publicado: Los Argentinos vienen de los peces: ensayo de filogenia nacional.

A Argentina - conhecida internacionalmente como o país de Ameghino - abre as considerações finais do livro. Essa é uma citação que já diz muito da importância e do significado dessa obra. Explico. Essa referência consta do primeiro artigo de Irina Podgorny sobre Ameghino, em Entrepasado, com que a autora inicia seus agradecimentos e que tive a oportunidade de ler quando começava a me encantar cada vez mais com seus textos, sem a conhecer pessoalmente. Retomá-la em Florentino Ameghino y Hermanos é como englobar 
todo um conjunto de uma enorme produção, sobre muitos temas da história das ciências, da arqueologia, da antropologia, da paleontologia. Desde o início de sua bem-sucedida carreira internacional, Irina Podgorny acompanhou e aprofundou os mais variados aspectos da saga paleontológica da empresa familiar de Ameghino e da história do sul da América que agora nos revela.

\section{Boa leitura.}

\section{AGRADECIMENTOS}

A autora agradece ao CNPq o apoio a suas pesquisas com Bolsa de Produtividade 1C. Projeto "Pesquisas paleontológicas: base para a busca de petróleo no Brasil (1907-1940)", processo n.303505/2018-4 -2019-2023.

\section{NOTAS}

${ }^{1}$ No original: "recuerdo sobre "collección de piezas grandes'". Nessa e nas demais citações de textos publicados em outros idiomas, a tradução é livre.

${ }^{2}$ No original: "probablemente lo único que se leyera en Buenos Aires pero irrelevante fuera del país".

\section{REFERÊNCIAS}

DASTON, Lorraine; SIBUM, H. Otto.

Introduction: scientific personae and their histories. Science in Context, v.16, n.1-2, p.1-8, 2003.

FREIRE JR., Olival. Biografia como gênero na história das ciências: o caso do físico David Bohm
(1917-1992). Circumscribere: International Journal for the History of Science, v.25, p.40-56, 2020.

PODGORNY, Irina. Florentino Ameghino y Hermanos: empresa argentina de paleontología ilimitada. Buenos Aires: Edhasa, 2021.

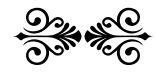

